\title{
General practice workload implications of the national service framework for coronary heart disease: cross sectional survey
}

\author{
Julia Hippisley-Cox, Mike Pringle
}

Standards one to four of the national service framework for coronary heart disease require general practitioners in England to identify all patients with established coronary heart disease or stroke, record their coronary risk factors, and offer appropriate treatment and to identify and treat patients at high risk of developing coronary heart disease. ${ }^{1}$ We estimated the general practice workload involved in meeting these goals.

\section{Participants, methods, and results}

We invited 65 practices randomly selected from the 51 primary care groups in the Trent region to participate; 24 practices volunteered and 18 were recruited. ${ }^{2}$ Ethical approval was obtained. We identified two target groups of high risk patients aged 35-74: patients with a Read code for ischaemic heart disease or stroke or at least one prescription for a nitrate (group 1), ${ }^{3}$ and patients with a computer recorded Read code for diabetes or hypertension (excluding those in group 1) who would be at high risk of developing coronary heart disease (group 2).

During March and April 2000, we extracted details of ischaemic heart disease, comorbidity (diabetes, hypertension, and stroke), drug treatment, and other coronary risk factors (age, sex, family history of cardiovascular disease, most recent smoking status, body mass index, blood pressure, glycated haemoglobin, and fasting lipid concentrations) from the practice computers. Descriptive data were analysed in SPSS (version 8) and Stata (version 5.0).
Of the 98137 registered patients, $10325(10.5 \%)$ patients aged 35-74 years had at least one of ischaemic heart disease, stroke, diabetes, and hypertension. Fasting serum cholesterol concentrations had been recorded for $2267 / 4455(50.9 \%)$ patients in group 1 and $2478 / 5870(42.2 \%)$ in group 2. Of these, $1527 / 2267(67.4 \%)$ patients in group 1 and 1809/ $2478(73.0 \%)$ in group 2 had fasting serum cholesterol concentrations $>5 \mathrm{mmol} / \mathrm{l}$, with $1448(63.9 \%)$ and $400(16.1 \%)$, respectively, taking lipid lowering agents. Of the 1076 patients with a recorded history of myocardial infarction, $692(64.3 \%)$ had received a $\beta$ blocker. Aspirin was being taken by 3213 (72.1\%) patients in group 1 and $1326(22.6 \%)$ in group 2. Reducing the blood pressure target from 160/90 to $140 / 85 \mathrm{~mm} \mathrm{Hg}$ (the current recommended target ${ }^{4}$ ) increased the number of high risk patients needing improved control from 2702/10325 (26.2\%) to 6375 $(61.7 \%)$. Of the 1839 patients with diabetes, 1518 $(82.5 \%)$ had a glycated haemoglobin value recorded on computer, and of these, $729(48 \%)$ had a value $\geqslant 7.5 \%$, which indicated moderate to poor glucose control.

The number of patients who needed risk factors recorded on computer or further disease control measures was estimated on the basis of the proportion of patients in the whole study population (table). Practices varied 14-fold in recording risk factors on computer and fourfold in the need for further disease control measures. We estimate that in the average practice of 10000 patients about 904 items will need recording and about 2221 disease control measures will be needed (see table).
Editorial by Toop and Richards

Division of General Practice, Nottingham University, Nottingham NG7 2RD Julia Hippisley-Cox senior lecturer in general practice Mike Pringle professor of general practice

Correspondence to: J Hippisley-Cox julia.hippisley-cox@ nottingham.ac.uk

BMJ 2001;323:269-70

Age-sex standardised estimates of computer recording and disease control measures needed for patients aged 35-74 with established cardiovascular disease, diabetes or hypertension in a practice with a total list size of 10000 patients. Values are means (ranges)

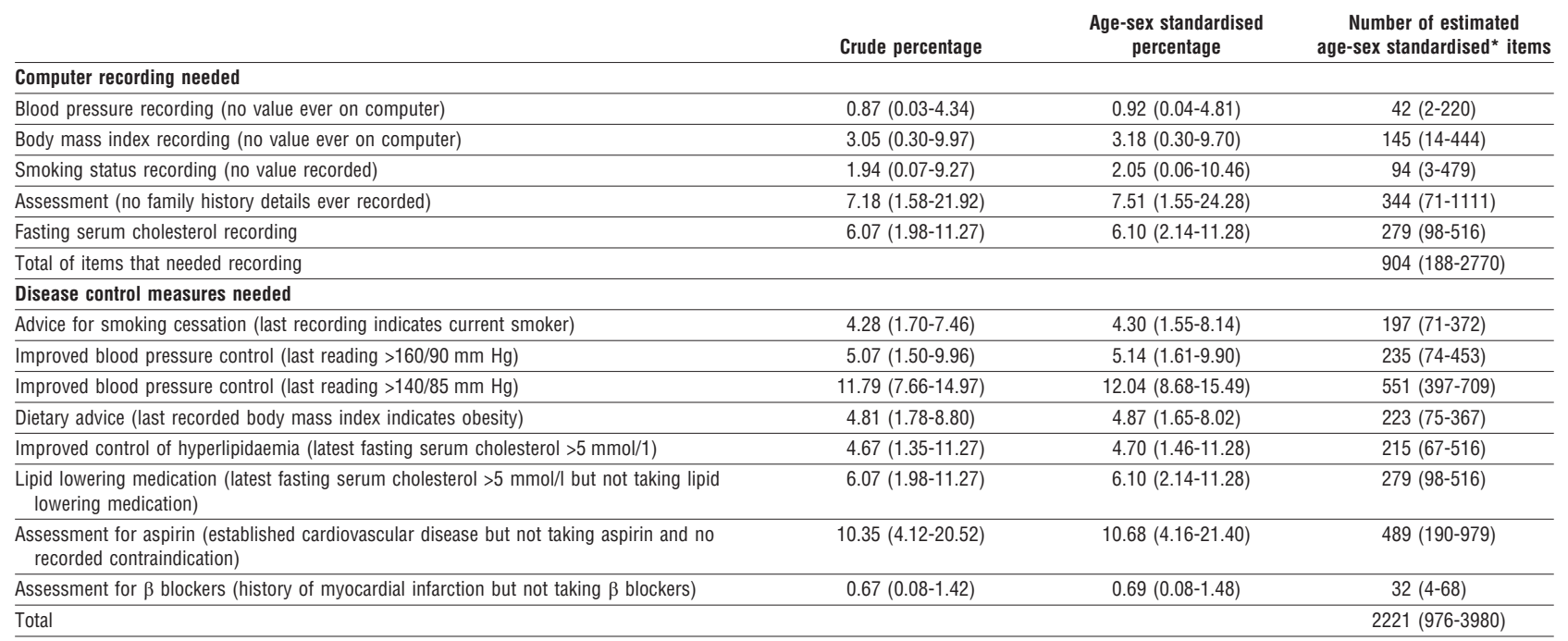

${ }^{*}$ Calculation assumes $45.75 \%$ of patients are aged $35-74$ as in 1998 UK reference population (Office for National Statistics). Direct age-sex standardisation to 1998 UK census data was undertaken using Stata (version 5.0). 


\section{Comment}

The national service framework for coronary heart disease has profound implications for primary care. Changes in workload and funding vary substantially between general practices.

Our estimates are conservative for a number of reasons. Practices in the study had systems compatible with MIQUEST (a computer software programme for data extraction) and their data might be of better quality than those from an average practice. We looked at data recorded on computers; examination of manual records and other information systems might reveal higher numbers of cases and better standards of care. We did not include patients without heart disease, diabetes, or hypertension who may have an absolute cardiovascular risk of $\geqslant 3 \%$ a year based on other risk factors. Our data included patients aged 35-74, but elderly patients have a higher cardiovascular risk and are more likely to gain from risk factor modification. ${ }^{5}$

Substantial variations in the recording of risk factors and the need for further disease control measures between practices were not explained by differences in the age-sex structure of the practice population. Some variation may be due to differences in how computer Read codes are used.

We thank the 18 general practices that took part in the study.

Contributors: JHC and MP initiated and designed the study. Nicola Crown, research assistant, and Andy Meal, lecturer in nursing, wrote the MIQUEST queries and organised the data collection. JHC designed and performed the data analysis. JHC and MP interpreted the results and drafted the paper. Carol Coupland, senior lecturer in statistics, advised on statistical revisions required by the editorial board. JHC is the guarantor of the paper.

Funding: Grant from Trent NHS Executive

Competing interests: None declared.

Department of Health. National Service Framework for Coronary Artery Disease: Modern Standards and Service Models. London: HMSO, 2000. www.doh.gov.uk/pdfs/chdnsf.pdf (accessed 17 May 2001)

2 Hippisley-Cox J, Pringle M, Crown N, Meal A, Wynn A. Sex inequalities in ischaemic heart disease in general practice: cross sectional survey. $B M J$ 2001;322:832-4.

3 Campbell N, Thain J, Deans H, Ritchie L, Rawles J. Secondary prevention in coronary heart disease: baseline survey of provision in general practice. BMJ 1998;316:1430-4

4 Ramsay L, Williams B, Johnstone G, MacGregor G, Poston L, Potter J, et al. British Hypertension Society guideline for hypertension management 1999: summary. BMJ 1999;319:630-5.

5 Smith GD, Song F, Sheldon TA. Cholesterol lowering and mortality: the importance of considering initial level of risk. BMJ 1993;306:1367-73.

\section{A memorable patient A dog's life}

In my role as respiratory educator in a family practice I made several follow up visits to a patient discharged from hospital with his first exacerbation of chronic obstructive pulmonary disease (COPD). These visits were to ensure that the patient, John, was recovering, had appropriate support, and understood his COPD self management plan.

On the first visit my arrival was heralded by an ageing, puffing, wheezing, snappy, arthritic chihuahua, which refused to leave me alone despite a volley of colourful language from his owner. The cluttered living area of John's home, where most of his time was spent, had an old cardboard box that the dog slept in, another for the cat, and a large cage for the cockatiel. The outside temperature was $30^{\circ} \mathrm{C}$ and it was hotter inside. The television set was loud, making conversation a challenge. The limping dog continued to wheeze and snap at my ankles. John warmly welcomed me and was genuinely pleased to discuss ways to manage his breathing on bad days. He had been discharged from hospital with a supply of prednisone $20 \mathrm{mg}$ tablets and some antibiotics, with written instructions about their use for deteriorating COPD. John was happy with his management plan and clear about using the drugs and when to contact the practice. Confident that he was well informed, I left, after arranging to see him again two weeks later. The dog saw me off the premises in the same manner that it had greeted me.

On the second visit, the yapping began as I touched the gate. When the gate opened I recoiled as the dog leapt up almost to my waist and continued to do so for the duration of my visit. It was a cooler day, and John looked well and was breathing without difficulty. I was concerned that he used some of the prednisone; when questioned, he said that they had been useful to stop the wheeze. We went over his management plan again and the need to contact the practice if his breathing deteriorated enough to use prednisone. In consultation with John's general practitioner we decided to continue with the same management plan. I was relieved to escape the constant harassment from the dog.

I approached the gate cautiously on my third visit, conscious that the dreaded dog was ready to pounce. Sure enough, it hurtled itself at me and then proceeded to run around with the vigour of a puppy. On entering the living area, I was immediately aware that the volume of the television was much lower than on my previous visits. As the dog continued its manic circling, I asked John about the change in its behaviour. "The prednisone," John replied. "He has one every four days. It fixes his wheeze and arthritis, and he has much more energy. It works for us both. I couldn't hear the television above his wheeze before. By the way, we need some more."

Stunned, I explained the danger of killing the wretched animal. John told me that his beloved pet was old, in pain, and unable to breathe easily. His rationale was that quality of life was better than quantity.

My most recent visit to John was to gain consent for this article to be published, and again the temperature was around $30^{\circ} \mathrm{C}$. In the middle of the living room floor were three new food plates for the dog, full of food and drink, each inscribed "Dog's Life."

Margaret Sutherland research coordinator, department of public health and general practice, Christchurch School of Medicine, University of Otago, New Zealand

We welcome articles of up to 600 words on topics such as A memorable patient, A paper that changed my practice, My most unfortunate mistake, or any other piece conveying instruction, pathos, or humour. If possible the article should be supplied on a disk. Permission is needed from the patient or a relative if an identifiable patient is referred to. We also welcome contributions for "Endpieces," consisting of quotations of up to 80 words (but most are considerably shorter) from any source, ancient or modern, which have appealed to the reader. 